\title{
Cross-national Deployment of "Graduate Jobs": Analysis Using a New Indicator Based on High Skills Use
}

\section{Golo Henseke and Francis Green}

UCL Institute of Education, University College London

\begin{abstract}
Utilising work task data drawn from the OECD's Survey of Adult Skills of 2011/2012 and 2014/2015, we derive a new skills-based indicator of graduate jobs, termed ISCO(HE)2008, for thirty-one countries. The indicator generates a plausible distribution of graduate occupations and explains graduates' wages and job satisfaction better than hitherto existing indicators. Unlike with the traditional classifier, several jobs in major group 3 "Technicians and Associate Professionals" require higher education in many countries. Altogether, almost a third of labour is deployed in graduate jobs in the 31 countries, but with large cross-national differences. Industry and establishment-size composition can account for some of the variation. In addition, two indicators of the relative quality of the higher education system also contribute to the variation in the prevalence of graduate jobs across countries.
\end{abstract}

Keywords: Graduate labour market, skill, wages, job satisfaction, higher education, labour demand, OECD

JEL Codes: I23, J21, J23, J24

\section{Acknowledgements}

An earlier version of this paper was presented to the PIAAC International Conference held in Amsterdam, 23/24/ November 2015. We are very grateful to participants and especially to our discussant Glenda Quintini of the OECD Directorate for Employment, Labour and Social Affairs for many helpful comments. We also thank Vanessa Denis of the OECD Directorate for Education and Skills for her assistance with the classification programme for those countries where there is restricted occupation information in the public-use files. Our specials thanks go to two anonymous referees and the editors of this journal, Sol Polachek, Konstantinos Pouliakas, Giovanni Russo and Kostas Tatsiramos for their invaluable comments that have helped to improve this paper.

This work was funded partly by the ESRC-funded LLAKES Centre for Research on Learning and Life Chances (ES/J019135/1) with an additional contribution from the ESRC/UKCES Strategic Partnership, and partly by the ESRC-funded Centre for Global Higher Education (ES/M010082/1). 


\section{Introduction}

A recurring issue for education policy-makers is the labour market effect of the long-term global mass expansion of higher education. Across North America, Europe and Asia, school leavers' educational aspirations have risen to the point that they are now more likely than not to proceed to tertiary education, and the consequences have for the last two decades been seen in the growing stocks of tertiary-educated labour in the workforce. Between 2000 and 2011 the proportion of the population (35-64 years old) with tertiary education had grown from $22 \%$ to $32 \%$ on average across OECD countries (OECD, 2013a), and the European Union has declared a common goal to reach a proportion of at least $40 \%$ graduates in the age-group 30-34 by 2020 (European Commission, 2014). By contrast, while the traditional destinations for graduates in professional and managerial occupations have expanded simultaneously, this rise has been to a much lower extent (Handel, 2012). If the large and ongoing rise of high-educated workers is to yield growth dividends and to meet new graduates' expectations for good jobs, the question arises: where are the jobs in which these graduates can adequately utilise their skills?

One way in which this question is sometimes addressed directly is through the lens of the concept of the "graduate job", and we take this approach here. Yet any such investigation begs the question as to how such jobs are defined and measured. Although the traditional notion of a "graduate job" in management or the professions lingers on in the language of elite HR recruiters from high-ranking universities and in the expectations of many students, we argue that there is need for a modern indicator which embraces a broader set of occupations and tasks, respecting the fact that, alongside the massification of higher education, there has been a prolonged period of skill-biased technological and organisational change and a globalisation of capital.

For a graduate job indicator to be useful for understanding graduate labour markets around the world, it is essential that it be rooted in the character of the job's skill requirements, whilst taking the relative national position of graduates on the labour market into account. In this paper, we develop and analyse a theoretically motivated, transparent classification of graduate jobs, using data from the Survey of Adult Skills (SAS) from the OECD's Programme for the International Assessment of Adult Competencies. The SAS is an international survey of key skills, skills use and socio-economic background of the adult populations aged $16-65$ years.

Using a method developed and validated using the British Skills and Employment Surveys (Green and Henseke, 2016a), we combine self-reported information on the qualifications needed to do the job competently with rich data on work tasks and further drivers of country-specific higher education demands, to derive an indicator of graduate jobs. The main idea is to uncover the variation in the selfreported higher education requirements that can be attributed to differences in work tasks across jobs. 
As our approach classifies ISCO-08 minor groups, the classification can be applied within countries to other general purpose surveys where occupation is coded to the ISCO framework. ${ }^{1}$

A key motivation for developing a graduate job indicator is to study the demand for graduate skills in the labour market. Though in most countries the graduate wage premium has been maintained through recent periods of $\mathrm{HE}$ expansion (OECD, 2014), there is some evidence of growing heterogeneity in the returns, linked in part to overeducation (Green and Zhu, 2010; Figueiredo et al., 2013; Lindley and Machin, 2016). Moreover, recent labour market intelligence suggests that the growth of graduate jobs in the US has come to a standstill (Beaudry et al., 2014; Beaudry et al., 2016). But the use of graduate labour at any one time is also likely to vary between national economies. In theory such variation should be associated inter alia with differences in the rate of technology adoption, in industrial composition, and in the relative price and quality of graduate labour compared with substitute labour. Applying our new graduate job indicator, we examine determinants of cross-national differences in the deployment of graduate jobs.

The paper is structured as follows. In Section 2 we develop a concept of graduate jobs and put forward a simple framework for the determination of the demand for graduate labour. Section 3 begins by considering issues surrounding existing graduate jobs classifiers. It then introduces the Survey of Adult Skills, describes the key variables capturing high skills use, and derives our classifier of graduate jobs. Its construct validity is examined in section 4 . Section 5 presents our findings from a cross-national analysis of the distribution of graduate jobs. Section 6 concludes and discusses some limitations.

\section{Concept and Theoretical Framework}

\subsection{The Concept of a Graduate Job}

Following Green and Henseke (2016a) we conceive of a graduate job as being one where most of the skills used are acquired in the course of higher education ${ }^{2}$, including many of the activities surrounding it, and in the course of ensuing or coterminous periods of work.

Graduate job skills are generally thought to comprise a combination of subject-specific professional skills, cognitive skills such as problem solving, knowledge creation, information-processing and management skills, as well as planning and people skills to mobilize others and oneself (Allen and Van der Velden, 2011; Barone and Ortiz, 2011). But it is not straightforward to determine the timing, source

\footnotetext{
${ }^{1}$ The International Standard Classification of Occupations 2008 (ISCO-08) is, as its predecessor ISCO-88, an international framework to classify and group occupational information. At the highest level of aggregation ISCO08 distinguishes between 10 major groups (1-digit). As we move down the hierarchy, these are broken down into increasingly nuanced occupational groups based on similarities in skill level and skill specialisation. Our approach will cluster occupational minor groups (3-digit) which form the second most detailed level of the ISCO-08 classification system. For more information on ISCO-08, see ILO (2012).

${ }^{2}$ Higher education can comprise both education programmes at universities that lead to a higher education degree as well as programmes at comparable levels at non-university education institutions such as polytechnics or university colleges. Access to higher education usually requires a qualification at upper secondary level. The importance of non-university higher education varies cross-nationally.
} 
and substance of skill acquisition. Graduates' skills are not just accumulated at university or colleges, but the product of a history of skill formation since early childhood (Heckman, 2007). Available family resources, the parental demand for children education, the curriculum during primary and secondary school, and exposure to heterogeneous teacher quality during compulsory schooling are some factors among many that determine the skill level with which school leavers enter higher education (Björklund and Jäntti, 2012; Björklund and Salvanes, 2011; Chowdry et al., 2013). Some graduate skills may also develop outside the formal learning experience of higher education. Field trips, for example, or coterminous employment (including work placements, internships or charitable work) provide opportunities for students to learn to apply taught skills productively (Crebert et al., 2004) and to build orchestration skills such as planning one's own work or the work of others (Allen, 2011). Moreover, higher education teaches not only subject-specific skills but also generic skills such as presentationgiving, project management, independent learning, delivering written documents on tight deadlines, solving complex problems and efficient learning strategies (Jackson, 2014).

Our proposed skills-focused concept of graduate jobs accommodates the heterogeneity of graduate skills and their sources. It differs from alternative approaches which focus either on occupational prestige (Ganzeboom and Treiman, 1996; Macmillan and Vignoles, 2013), or more specifically on the professions (Milburn, 2009; Allen and Van der Velden, 2011) or, in line with human capital theory, on whether higher education is especially highly-valued within that occupation by the labour market (Cardoso, 2007; Gottschalk and Hansen, 2003; O'Leary and Sloane, 2016). These alternative classifications overlap with ours: for example, skills usage, occupational prestige and pay are usually higher for "professional" occupations and so these occupations will be classified as graduate jobs under all approaches. The different outcomes arise with other major groups (mainly, managers and associate professional/technical occupations). Yet in our approach, concentrating on the functional side of jobs, skills use, allows us to identify graduate jobs based on the tasks people carry out during their work and whether they require higher education to do so competently. This classification approach has the most direct connection to the theoretical concept.

\subsection{Demand for graduate labour: theoretical expectations}

While there is an inevitable fuzziness at the margin in any definition of a graduate job the concept is nevertheless widely used, because it has considerable analytic utility for the understanding of graduate labour markets. There are concerns in both western and Asian nations that the supply of graduate labour is outstripping the numbers of graduate jobs (e.g. Wilson, 2012). Theory implies that the demand for graduates depends, first, on the extent to which high skills are demanded in the economy and, second, on the extent to which higher-educated labour delivers high skills. Both these links could be expected to vary across countries and over time.

The widespread shift towards high-skill jobs is not new; it has been ongoing for at least several decades (Handel, 2012). The main attributed global drivers have been technological and organisational changes, alongside the evolving global division of labour. The emphasis has mainly been on technological change 
(Acemoglu and Autor, 2011; Machin and Van Reenen, 1998; Van Reenen, 2011); ICT, especially, is held to have raised the productivity of graduate workers over the last 30 years or so. This skill biased technological change (SBTC) is thought to be the principle driver behind the growth in the demand for graduate labour.

Nevertheless, it is by no means certain that contemporary technological change is leading to an ongoing upskilling of jobs. An alternative scenario has been painted by some commentators of a divergence of opportunities for graduate labour, with computerisation now leading to "digital Taylorism" and associated de-skilling of the bulk of graduate jobs, with only a minority of especially talented graduates from elite institutions continuing to enjoy ever increasing favour in the labour market (Beaudry et al., 2014; Beaudry et al., 2016; Brown et al., 2011). Resolution of these contrasting predictions may only emerge as the future unfolds, but it remains useful to ask whether the distribution of graduate jobs in the current era is positively linked to technology, and work organisation.

While transferable technology is likely to be widely diffused, it is expected nevertheless that the pace of absorption varies according to the capacity of firms and their employees to absorb new techniques and processes (Zahra and George, 2002). Management skills and systems of work organisation are among the important factors influencing such absorptive capacity. Quintini $(2011,2014)$ has found substantive cross-country variation in skills utilisation levels, associated in part with variations in labour productivity.

Some cross-national/cross-regional variation in the demand for high-level skills, and thereby in the prevalence of graduate jobs, could therefore be expected. Equally SBTC leads to the expectation of a generalised increase over time in the prevalence of graduate jobs, though if counter-tendencies come to predominate the opposite expectation arises.

A second factor in the demand for graduates is the relative cost and availability of alternatively-educated, substitutable, high-skilled workers. Not only HE systems, also national VET systems vary hugely, with consequences for the relative quality of university graduates compared to the closest substitutable educational level (Eichhorst et al., 2015). At least some of the high-level skills could be acquired through vocational and work-based learning routes. Similarly, labour market norms and institutions affect the way skills are formed through work experience and rewarded for example during the schoolto-work transition (Pastore, 2015). What matters, therefore, is the quality of graduate labour relative to potential substitutes. Germany, in particular, is noted for its effective "dual" apprenticeship system, including high-level vocational skills for a sizable minority of the labour force; while Japan's internal labour markets are held to be efficient vehicles for in-work acquisition of high-level skills (Koike and Inoki, 1990). In short, we expect there to be cross-country differences in the mapping from work tasks to educational demands, reflecting the relative qualities and costs of graduate and vocationally-educated labour. In a country where high-skilled substitutable vocational labour is available, employers design fewer jobs ceteris paribus as graduate jobs. This expectation is the second reason for international variation in the use of graduate labour and calls for a classification of graduate jobs that is flexible 
enough to accommodate country-specific mappings from work tasks to educational requirements. Below, Section 5, we operationalise these drivers to provide a provisional account of how the prevalence of graduate jobs varies across countries.

\section{Data and Indicators}

\subsection{Existing Indicators of Graduate Jobs}

Existing studies propose diverse principles for conceiving graduate jobs and utilise varied methods for deriving indicators. Most frequently used is the simple, prestige-based, traditional classification based on being coded in one of the first two major ISCO groups - Managers or Professionals. To recognise the need to modernise this classification by going beyond the traditional approach, recourse is sometimes made to the idea that graduate jobs are defined by what graduates do. This approach utilises the concept of realized matches to approximate the required level of education from the modal, median or mean education level held by workers within occupations. While this approach can be delivered in a subtle way that takes account of the age structure of occupations, and allows for exceptions or niches to be identified as graduate jobs (e.g. Elias and Purcell, 2004), at least in its simplest form this supply-driven approach is subject to the criticism that it is tautological and of limited use for analytical purposes. To replace such an approach with a conceptually more satisfactory skills-based perspective, expert-based classificatory mechanisms may be available (e.g. Elias and Purcell, 2013, for the UK) which deploy knowledge about the tasks involved in occupations to make judgements about whether they require graduate-level skills. Some of this knowledge can be gleaned from detailed job titles. Yet, expert-based classification methods remain somewhat subjective, lack transparency in their method (so are hard to replicate and update), and could not be extended to an internationally comparable classification except perhaps at enormous cost.

A further method has been to identify occupations as graduate jobs when there is evidence that graduates are offered a premium within that occupation (e.g. Gottschalk and Hansen, 2003). Rooted in an assumption about the competitiveness of labour markets where scarce skills are rewarded when demanded, this method has the merit of avoiding use of self-reported job assessments. Yet it has the disadvantage that it relies on gaining unbiased estimates of within-occupation returns, which is rendered nearly impossible by the fact that occupational selection and human capital returns are closely interlinked. Moreover, the method cannot then be utilised as a tool for analysing wage returns without, again, risking tautology. The wage-returns approach would also be highly questionable when applied in an international comparative perspective, because there is a large international diversity in the effects of labour market institutions on wages.

Among existing indicators, only the traditional indicator and the supply-driven methods lend themselves to an international approach. But since neither of these seems remotely adequate in the context of the modern world, with changing skills demands rendering the traditional measure out of date, and rapidly growing graduate stocks covering supply-driven indicators with a thick layer of tautology. A better 
method is warranted, and one that does not simply add on further major occupational groups indiscriminately without considering the concept of what a graduate job is.

If neither expert-based nor existing statistical methods are entirely fit for purpose to identify graduate jobs, could it be prudent to ask workers directly about their jobs' educational requirements? It is argued elsewhere that workers are generally well suited to assess the skill and qualification requirements of their job. ${ }^{3}$ But responses to a single item will carry errors, affected by individual's self-esteem or facets of the job that are unrelated to skills usage. If unrecognised, these errors would be conveyed to the resulting indicators. An indicator of whether graduate skills are required in an occupation should aim to be purged of such errors.

In the next section we develop such an indicator. The procedure uses work task indicators to uncover the variation in self-reported qualification requirements that is attributable to differences in high skills demands. The classification captures the use of graduate skills independently of the sources of skills. It does not rely on assumptions about the link between higher education and wages within occupations. The method avoids the use of hard-to-replicate expert judgements and deploys an observer-neutral classification procedure, based on relatively simple statistical classification methods, while not relying on single survey item responses. The result is a transparent procedure, and an indicator that is flexible enough to allow for country differences in graduate jobs and which can be consistently amended over time as technologies and workplaces evolve.

\subsection{The Survey of Adult Skills}

We use data from the Survey of Adult Skills (SAS), which is an international survey as part of the OECD's "Programme for the International Assessment of Adult Competencies" (OECD, 2013b). The fieldwork for the first round was conducted between 2011 and 2012 in 24 countries; a second round in 2014/2015 added data for further nine countries. The sampled population in each country is the adult population aged 16 to 65 years. Overall, more than 215,000 people were assessed in three proficiency domains - literacy, numeracy and problem solving skills in "technology-rich environments" - and interviewed on topics covering use of skills at work and at home, the work experience, continuing training, and personal characteristics such as qualifications, family background or health. Around 5,000 interviews were carried out per country. A harmonized sampling procedure, a standardized questionnaire and shared classifications for industry, qualification and occupations ensured high comparability across countries. To proceed we pool the available country data files into one international dataset.

In all, we have information for 31 countries/ country-regions to identify graduate jobs: Austria, Belgium (Flanders), Canada, Chile, Cyprus, Czech Republic, Denmark, Estonia, Finland, France, Germany, Greece, Indonesia, Ireland, Israel, Italy, Japan, Korea, Lithuania, Netherlands, New Zealand, Norway,

\footnotetext{
${ }^{3}$ There is no evidence of a substantial, systematic, bias in workers' self-assessments of their jobs, but there is a possibility of a small gender bias (Green and James, 2003).
} 
Poland, Singapore, Slovak Republic, Slovenia, Spain, Sweden, Turkey, United Kingdom (Engl./ Nr. Irl.), United States. This country selection covers different levels of development and various types of education and training systems with varying trajectories in higher education. We excluded the Russian survey data from our analysis because of data quality concerns (OECD, 2013c).

SAS uses a complex sample design to achieve representativeness for the country target populations. To adjust for the sampling procedure, in the analyses that follow we make use of the provided probability weights to derive the correct parameter estimates.

\subsection{Work Tasks and Skill Indicators}

The SAS data have already been utilised to derive novel measures of skills mismatch among all employees (Allen et al., 2013, Pellizzari and Fichen, 2013). In contrast to these studies, we are specifically concerned here with the utilisation of graduate skills in the labour market

The indicator will classify minor group (3-digit) occupations, defined by the International Standard Classification of Occupations 2008 (ILO, 2012), according to whether they are graduate or non-graduate jobs. ISCO08 provides a consistent and internationally comparable framework to classify occupations, consisting of four hierarchical levels with increasingly detailed occupational groups. At the most detailed level it differentiates between 436 unit groups, which are structured into 130 minor groups and 43 sub-major groups. The top level is formed of 10 major groups: Armed Forces Occupations; Managers; Professionals; Technicians and Associate Professionals; Clerical Support Workers; Services and Sales Workers; Skilled Agricultural, Forestry and Fishery Workers; Craft and Related Trade Workers; Plant and Machine Operators and Assemblers; and Elementary Occupations.

The selected indicators are motivated by the concept of graduate jobs outlined in the section above. We have constructed multiple variables which will form the ingredients of the classification:

Workers in SAS are asked to assess the qualification required to get their current job; independent from their individually held qualification. In other words, non-graduates may report that their job requires higher education. Because there may be credentialism - where a qualification is asked for, but not necessary for doing the job, respondents are also asked whether the qualification is also needed to perform the job satisfactorily. The information is dichotomised according to the coding scheme in Table 1. Higher education is required to do the job if workers state that a qualification at Bachelor level (ISCED5A) or above is needed to carry out the job competently. In cases where a master or doctoral degree is necessary to get but not essential to do the job, we conjecture that a shorter higher education course will nonetheless be required to perform the job tasks satisfactory. ${ }^{4,5}$ This variable captures higher

\footnotetext{
${ }^{4}$ There is an idiosyncrasy in the available British microdata with respect to the ISCED codes. Higher education is subsumed into one category (graduate, post-graduate and PhD level). We assume that a Bachelor degree will suffice to get most of the graduate jobs in Britain and treat the category accordingly within our coding scheme.

${ }^{5}$ In Denmark and Flanders, there were some graduate level jobs in sub-major group "95 Street and Related Sales and Service Workers". A closer inspection of the industry codes and the skill use on the job suggests that, despite the precautions by the PIAAC consortium, the occupations were most likely miscoded.
} 
education requirement as reported by workers and is the key information in the following, but since the assessment may be influenced by other factors than job skill requirements, we complement the information with further data on job tasks.

Table 1: Coding of self-reported higher education requirements on the job

\begin{tabular}{lll}
\hline $\begin{array}{l}\text { IF (Higher education required } \\
\text { to get the current job) }=\end{array}$ & $\begin{array}{l}\text { AND (Also needed to perform } \\
\text { the current job) }=\end{array}$ & $\begin{array}{l}\text { THEN (Higher education } \\
\text { required to do the job) }=\end{array}$ \\
\hline ISCED 6 & Yes OR No & Yes \\
ISCED5A - Master & Yes OR No & Yes \\
ISCED5A - Bachelor & Yes & Yes \\
& No & No \\
<=ISCED5B & Yes OR No & No \\
\hline
\end{tabular}

The SAS background questionnaire covers a comprehensive list of cognitive and interactive work tasks in areas such as literacy (reading and writing documents), numeracy (calculation of budgets, usage of simple algebra), the level of computer use, problem solving, organising (own work and others), and communicating (presenting, teaching). In addition, the microdata files of SAS include broader work task scales derived from combinations of a selection of single work task items. The scales are derived by the PIAAC consortium using Item Response Theory. The single items capture the frequency with which each task is performed, ranging in four steps from "Less than once a month" to "Every day".

We deploy a subset of the task items, a selection of the provided task scales and some related variables to measure demand for high-level information procession and orchestrations tasks, which are conjectured to contribute to greater higher education requirements. Each variable is dichotomised with a value of one if respondents perform a specific task at least weekly (for single task items) or fall into the highest category of the included SAS task scale, and zero otherwise. The items on information procession cover high-level numeracy, reading and regular writing of letters/memos/ emails as well as regular complex problem solving and high-level computer use. Using the same principles, information on regular teaching, presenting, influencing, and supervisor responsibilities for more than 5 employees are used to summarise orchestration tasks.

Higher job autonomy is another aspect that is generally theorized to set graduate job apart from nongraduate jobs. Planning one's own work, prioritizing tasks, and regulating the pace of work requires skills. SAS data include items on self-planning and work flexibility. Job autonomy is assessed by items on facets of discretion covering discretion over how work tasks are set, how work is done, the speed of work and working hours as well as the need to plan their own work activities and work time. The single indicators are dichotomised with values of one if respondents report very high levels of discretion for each flexibility item or state that self-planning skills are required at least on a weekly basis. Job 
autonomy is a multi-dimensional concept; the final scale is therefore calculated as the average over the included items. ${ }^{6}$

Some graduate jobs potentially require work-specific skills in addition to formal education. Therefore, we also include a binary variable that captures whether three or more $3+$ years of experience are required to get the respondent's current job. Required work experience is not an exclusive feature of graduate jobs, but it is thought to capture otherwise unobserved knowledge requirements that add to the demand for high level skills. ${ }^{7}$

Though the list of job tasks is relatively rich, we may not capture all systematic differences in higher education requirements between jobs. Therefore, we include a variable that measures the higher education requirements in similar jobs. ISCO groups similar jobs in terms of required skill level and skill specialisation together. We exploit this construction principle to define for each worker a neighbourhood of similar jobs, which include observations within the same minor group (3-digit occupation) in the same country. The indicator is calculated as the average demand for higher education in the neighbourhood. Formally,

$$
\widetilde{H E}_{i}=\frac{1}{K(i)} \sum_{k=1}^{K} H E_{k(i)}
$$

where $k(i)$ describes the set of observations within the same minor group and same country as job $i$, $H E_{k(i)}$ captures the need for higher education to carry out job $k$ in the neighbourhood of respondents $i$ 's job, and, finally, $\widetilde{H E}_{i}$, represents the average level of higher education requirement in the neighbourhood of job $i$. The variable captures systematic differences in the need for higher education over and above job tasks.

Table 2 summarises the descriptive statistics of complete list of indicators for the pooled sample of 31 countries.

Table 2: Summary Statistics (N=94,925)

\begin{tabular}{lcccc}
\hline Variable & Mean & Std. Dev. & Min & Max \\
\hline HE required & 0.242 & 0.428 & 0 & 1 \\
HE required (similar jobs) & 0.238 & 0.294 & 0 & 1 \\
3+ years of experience required & 0.238 & 0.426 & 0 & 1 \\
Information Processing Tasks & & & & \\
High level numeracy & 0.181 & 0.385 & 0 & 1 \\
High level reading & 0.212 & 0.409 & 0 & 1 \\
Writing memos/ mails & 0.524 & 0.499 & 0 & 1 \\
Complex problem solving & 0.376 & 0.484 & 0 & 1 \\
High level computer use & 0.149 & 0.356 & 0 & 1 \\
Orchestration Tasks & & & &
\end{tabular}

\footnotetext{
${ }^{6}$ With Cronbach's alpha for the resulting scale of 0.74 , one could plausibly regard this scale as capturing a single latent construct of "high autonomy".

${ }^{7}$ Of course, for entry level graduate jobs, work experiences may not be essential or even be desired.
} 


\begin{tabular}{lllll} 
Regular teaching & 0.359 & 0.480 & 0 & 1 \\
Regular presenting & 0.153 & 0.360 & 0 & 1 \\
Regular influencing & 0.518 & 0.500 & 0 & 1 \\
Supervising & 0.156 & 0.362 & 0 & 1 \\
Job Autonomy scale & 0.358 & 0.251 & 0 & 1 \\
\hline
\end{tabular}

This list of work task measures is neither exhaustive nor will every graduate job necessarily demand high levels of each variable. On their own none of the listed tasks is an essential facet of graduate jobs. We argue, however, that the defined variables capture different aspects of graduate jobs which, in combination, capture the non-routine cognitive and interactive-intensive characteristics that distinguishes graduate from non-graduate positions.

\subsection{Constructing ISCO(HE) 2008}

The classification procedure, which builds on our earlier work (Green and Henseke, 2016a), entails three steps. Firstly, we estimate at the micro-level how the above described work tasks map to a job's latent 'higher education requirement'. Next we average the predicted 'higher education requirement' across occupation-country cells. And finally, based on the resulting higher education requirement index, we partition occupations into a group of graduate and non-graduate jobs.

First, we map the stated qualification requirements to work task items by running a probit regression of the self-reported graduate job indicator $\left(H E_{i}\right)$ of individual $i$ on the work task items $\left(J S R_{i}\right)$, the higher requirements in similar jobs $\left(\widetilde{H E}_{i}\right)$, demographic controls $\left(X_{i}\right)$, and country fixed effects $\left(u_{j}\right)$. All variables are measured at individual level. The probit estimation represents an underlying latent variable model that captures the higher education requirements of an individual job. The model parameters are free to vary across countries to allow for country-specific mappings of work tasks to educational demands. The objective is to retain the variation in the latent variable that is attributable to observed differences in task across jobs. Systematic differences in work content by sex and age that are not captured by differences in generic tasks are controlled for by the inclusion of demographic confounders. Random reporting error is captured by an error term $\varepsilon_{i}$. Table 3 reports the resulting average mapping of the task items to the latent demand for higher education across all included countries based on the pooled sample from all countries.

Table 3: Mapping of work tasks to latent higher education requirements. Average Probit Effects

\begin{tabular}{lc}
\hline \multicolumn{1}{c}{ Variable } & $\boldsymbol{\beta} /(\mathbf{S E})$ \\
\hline High level numeracy & $0.124^{* * *}$ \\
& $(0.015)$ \\
High level reading & $0.230^{* * *}$ \\
& $(0.015)$ \\
Writing memos/ mails & $0.401^{* * *}$ \\
& $(0.015)$ \\
Complex Problem Solving & $0.156^{* * *}$ \\
& $(0.013)$ \\
High level computer use & $0.127^{* * *}$ \\
& $(0.016)$
\end{tabular}




\begin{tabular}{lc} 
Regular Teaching & $0.0318^{* *}$ \\
& $(0.014)$ \\
Regular Presenting & $0.193^{* * *}$ \\
& $(0.017)$ \\
Regular Influencing & 0.0102 \\
& $(0.014)$ \\
Supervising & $0.0518^{* *}$ \\
Job Autonomy scale & $(0.016)$ \\
& $0.094^{* *}$ \\
\hline 3+ years of experience required & $(0.03)$ \\
& $0.279^{* * *}$ \\
HE required (similar jobs) & $(0.015)$ \\
& $2.985^{* * *}$ \\
\hline Observations & $(0.023)$ \\
\hline
\end{tabular}

Note: Pooled probit coefficients over 31 countries. Demographic controls include age-group dummies $(<25,35-44,45-54$, 55+, with 25-34 as reference group) and sex. Sample of the employed labour force aged 16-65. Standard errors statistics in parentheses. $* \mathrm{p}<0.05, * * \mathrm{p}<0.01, * * * \mathrm{p}<0.001$

Generally, requirements for higher education at job level increase with greater information processing and orchestration tasks as well as with job autonomy. Information processing, particularly literacy task, receive the largest weight. But job autonomy, professional communication tasks (presenting, teaching, influencing), supervisor status emerge as further important contributors to higher education requirements.

Next, from the probit coefficients, we predict job-specific higher education requirements from the included covariates and the estimated country-specific probit coefficients. The mean of the predicted higher education requirement score is -1.112 and its standard deviation $1.215 .^{8}$

In the second step, we average the score across minor group (3-digit occupation) country cells. For cells with fewer than five observations, we impute the resulting index with the average value from the 2-digit occupation. This affects $19 \%$ of all minor group-country cells. There is the risk that we impute from overly coarse occupational groups that do not properly reflect the educational requirements for the subsumed minor-groups. However, further analysis shows that 2-digit occupations explain the variations in graduate skills requirement index well. ${ }^{9}$ The distribution of the resulting Higher Education Requirement Index (HERI), illustrated in Figure 1, varies clearly across major groups. It is generally highest, as expected, among Managers (1) and Professionals (2), with Technicians and Associate Professionals (3) somewhat lower. Nevertheless, there are substantial variations within the broad groups.

Figure 1: Box Plot of the Higher Education Requirement Index by ISCO Major Groups 1-9 (excluding outliers and armed forces)

\footnotetext{
${ }^{8}$ Probit estimates coefficients up to scale. The predicted latent higher education requirement score is thus unit free. However, the value can be plugged into the cumulative distribution function of the standard normal to derive the predicted probability that job $i$ requires higher education. The average value of -1.112 corresponds to a predicted probability of 0.133 .

${ }^{9}$ At the level of jobs, 3-digit occupations explain $75 \%$ of the variance in the predicted higher education requirement score, compared with $71 \%$ for 2 -digit occupation codes.
} 


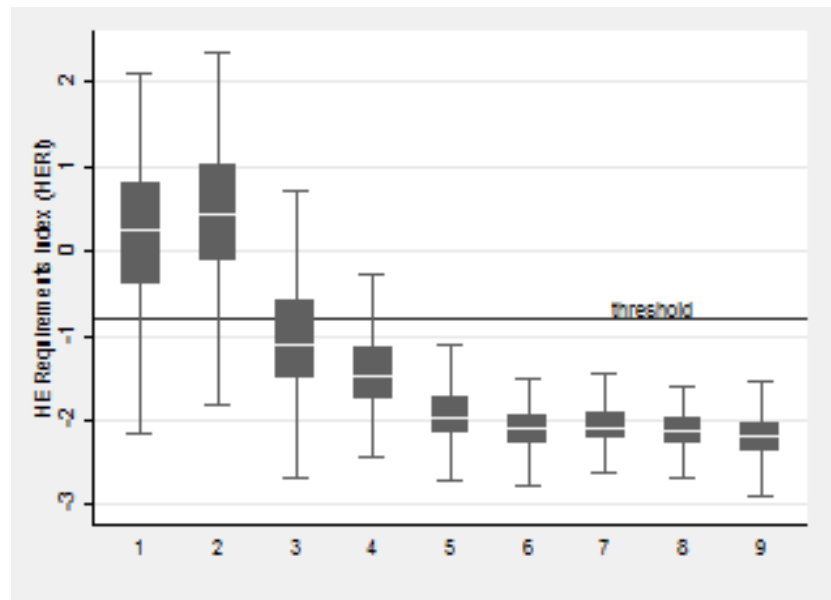

Note: The box plot displays the distribution of the higher education requirement index. The upper and lower edges of a box represent the $75 \%$ and 25\% Quartile, respectively. The median is given by the horizontal line within each box. The distance from the upper to the lower edge give the Interquartile Range (IWR); a measure of dispersion. Finally, median plus and minus 1.5 IQR determine the position of the whiskers. Outliers are not reported. Data covers all 31 countries.

In the final step, we partition occupations into graduate and non-graduate groups using k-medians cluster analysis on the higher education requirement index. With outliers a potential issue, the k-medians algorithm is more robust than the similar, well-established, k-means algorithm (Everitt et al., 2001). Since country differences in the mapping of work tasks to education requirements are taken into account in the first step, a given level of the higher education requirements index should be associated with the same realised demand for higher education credentials. Consequently, graduate jobs will have similar latent higher education requirements across countries but may differ in the actual skills demand. We impose a two-cluster solution with the same cut-point between graduate and non-graduate jobs across countries. The algorithm assigns occupations to a cluster by minimizing the distance between the occupation-specific HERI value and the cluster's centre. All occupations with a HERI score above the derived threshold are labelled "graduate jobs", whereas occupations below the threshold are referred to as "non-graduate" jobs. The resulting cut-point between graduate and non-graduate jobs is at -0.809 . Its relative position is displayed in Figure 1.

We term the resulting classification $I S C O(H E)$ 2008. The proportion of graduate level minor groups varies between $25 \%$ in Austria and Slovenia and $48 \%$ or above in Finland and Cyprus. The classification broadly confirms ISCO's mapping of higher education to the first two major groups, but also implies that the definition is too rigid at least for some countries where occupations outside of this narrow group require higher education. Several occupations in major group 3 are included as graduate jobs in many countries: for example, in more than half of the countries, jobs as "Administrative and specialised secretaries" (334) or "Regulatory government associate professionals" (335) make use of graduate skills. Further, in a few countries there is a small number of graduate level occupations in major group 4. Moreover, not all occupations in major groups 1 and 2 are graduate jobs. For example, neither "141 Hotel and Restaurant Managers" nor "265 Creative and performing artists" require higher education credentials to perform their duties except in a small minority of countries. The full list of graduate and non-graduate minor groups in each country is given in the appendix. Sensitivity analyses suggest that 
the derived classifier is overall robust. Apart from changes at the margin between graduate and nongraduate jobs, where some ambiguity is to be expected, the resulting classification of occupations proves stable to changes of the list of included countries and covariates in step one. We highlight a 'grey area' of occupations around the threshold where the classification is not strictly decisive in grey in the appendix.

\section{Criterion Validity: Labour Market Outcomes of Matched and}

\section{Mismatched Graduates}

Grounded in the principle that a graduate job entails high skills use, ISCO(HE)2008 presents, as shown above, a prima facie plausible distribution of graduate jobs across major occupations, with few anomalies. It suggests that graduate jobs should be defined more broadly than is implied by the traditional definition. Yet can one be confident that this new, theoretically consistent, indicator is more useful than existing indicators for analytical purposes? In Green and Henseke (2016a) our indicator, derived by the same method using British data and occupational codes, received validation support, in that it performed better than alternative graduate job indicators as predictors of wages, job satisfaction, training and matching outcomes. In this section we examine the criterion validity of ISCO(HE)2008, by investigating in our multinational sample the association of the indicator with two expected labour market outcomes: wages and job satisfaction.

We compare the performance of ISCO(HE)2008 against traditional definitions, which we term ISCO(1\&2)2008 and ISCO(RM)2008. The former is expert-based and classifies the first two major groups, with the exception of sub-major group "14 Hospitality, Retail and Other Services Managers", as graduate jobs and other groups as non-graduate (ILO, 2012). The latter follows a statistical approach by approximating education requirements by what graduates do; a sub-major group is deemed a graduate job if the majority of workers holds a degree from higher education. Sub-major groups are classified country-by-country. Table 5 summarises the three graduate job classifiers that will be compared in the following.

Table 5: Graduate Job Classifiers

\begin{tabular}{|l|l|}
\hline Classifier & Description \\
\hline ISCO(HE)2008 & $\begin{array}{l}\text { Higher educational requirements statistically identified from job } \\
\text { skill requirements as reported by workers. 3-digit occupations } \\
\text { with estimated higher education requirements above the cut- } \\
\text { point are deemed graduate jobs }\end{array}$ \\
\hline ISCO(1\&2)2008 & $\begin{array}{l}\text { Higher education requirements based on expert assessment of } \\
\text { occupational skill use. Occupations in ISCO major group 1 and } \\
\text { 2 with exception of sub-major group "14 Hospitality, Retail and } \\
\text { Other Services Managers" are deemed graduate jobs }\end{array}$ \\
\hline ISCO(RM)2008 & $\begin{array}{l}\text { Higher education requirements assessed statistically by the } \\
\text { frequency of graduates within occupations. Sub-major groups } \\
\text { where the modal worker holds qualification from higher } \\
\text { education are deemed graduate jobs. }\end{array}$ \\
\hline
\end{tabular}


The better the classification of graduate jobs, the more accurately it should predict expected labour market outcomes. Comparisons with ISCO(1\&2)2008 and ISCO(RM)2008 can establish whether there is a gain in adopting ISCO(HE)2008 rather than these existing classifications. These outcomes are captured as follows:

- Log Hourly Wages: The natural logarithm of the hourly earnings including bonuses for wages and salary earners, converted to PPP-\$. Values in the $1 \%$ and $99 \%$ percentile have been removed to protect against potential distortions from outliers.

- Job Dissatisfaction: Question on job-satisfaction with values ranging in five steps from 1 "Extremely satisfied" to 5 "Extremely dissatisfied". Job dissatisfaction is defined as a binary variable that distinguishes satisfied (categories 1 and 2) from dissatisfied workers (responses 3, 4 and 5).

For the validation, we focus on the fraction of the labour force in occupation major groups one to four. This is the high-skills and middle-skills intensive range of the labour force where higher education may be required for some but not all jobs. And this is also the range of the occupational classification where the classifiers differ in detail. ${ }^{10}$

We expect graduates in graduate jobs to earn higher wages and to have fewer reasons to be dissatisfied with their job, compared with graduates in non-graduate jobs (Green and Zhu, 2010; Vieira, 2005). The top panel of Table 6 reports the results from linear regressions of the dependent variables on the graduate job classifiers and a common set of covariates (set of dummy variables for age group, gender, foreignborn, and a dummy for public sector employment) in the sample of employed graduates. The results confirm that, for graduates, working in graduate jobs is associated with a significant pay premium and a smaller probability of expressing dissatisfaction with the job. ISCO(HE)2008 gives the largest pay premium whilst estimated effects on job satisfaction are similar across classifiers. Values for R-squared are close to each other.

In line with the concept of graduate jobs, we expect graduates to be better rewarded in graduate jobs than substitute labour (Gottschalk and Hansen, 2003). The latter we define here as those with 'advanced vocational education' credentials who may possess high-level skills and thus be deployed to perform complex work tasks similar to those in graduate jobs. ${ }^{11}$ Accordingly, the middle panel of Table 6 compares the labour market outcomes of graduates with those of other high-skilled labour. The interaction term between HE and being in a graduate job shows that only ISCO(HE)2008 predicts a

\footnotetext{
${ }^{10}$ Because 2-digit occupation and hourly pay are withheld from some of the publicly available national microdata files, the validation is conducted for a subset of countries. Austrian, Canadian, Estonian and Finnish data does not contain information on 2-digit occupation that is needed to derive ISCO(RM)2008. In addition, hourly pay is missing for Singapore, Sweden, Turkey and the United States. Wage regressions are thus restricted to observations from the remaining 23 countries.

${ }^{11}$ This group generally comprises individuals with qualification at ISCED 4 and 5B level. However, in Italy, the Netherlands and the Slovak Republic only a minute proportion hold qualifications at these levels $(<4 \%$ of the labour force). Therefore, in these countries the closest feasible substitute to graduate labour are all people with upper-secondary qualifications and below higher education.
} 
significant wage premium as well as a lower job dissatisfaction for graduates within graduate jobs. Graduate jobs defined by ISCO(1\&2)2008 or ISCO(RM)2008 do correlate with higher pay and less job dissatisfaction in general; but higher education per se was not associated with greater returns within these traditionally defined graduate jobs.

Finally, we compare labour market outcomes in jobs whose positioning is contested across the classifications. Building on Gottschalk and Hansen's (2003) insight that graduate jobs add to the returns of higher education, we estimate the returns in jobs which are categorised as graduate by both the traditional approaches and our classifier and compare the results with those for jobs that are classified as graduate (non-graduate) by ISCO(HE)2008 but as non-graduate (graduate) by the traditional approaches. If our classification is to be better, we would expect that the rewards to higher education in the latter group of graduate (non-graduate) jobs should be similar with other graduate (non-graduate) jobs. Table 6.1 summarises the returns to higher education over advanced vocational qualifications by occupational categories. We compare our classifier against ISCO(1\&2)2008 and ISCO(RM) 2008. For each comparison occupations breakdown into four categories: non-graduate $[$ both: $\operatorname{ISCO}(\mathrm{HE})=0$ and $\operatorname{ISCO}(\cdot)=0]$, non-graduate $[\operatorname{ISCO}(H E)$ only: $\operatorname{ISCO}(\mathrm{HE})=0$ and $\operatorname{ISCO}(\cdot)=1]$, graduate $[\operatorname{ISCO}(H E)$ only: $\operatorname{ISCO}(\mathrm{HE})=1$ and $\operatorname{ISCO}(\cdot)=0]$ and graduate $[$ both: $\operatorname{ISCO}(\mathrm{HE})=1$ and $\operatorname{ISCO}(\cdot)=1]$, where $\operatorname{ISCO}(\cdot)$ denotes either ISCO(1\&2)2008 or ISCO(RM) 2008 depending on the comparison.

Firstly, the returns to higher education in 'ISCO(HE) only' non-graduate jobs are not clearly statistically different from those in jobs that are defined as non-graduate by both ours and existing classifiers. Neither in the first ( $0.110 \mathrm{vs}-0.009$, column 1$)$ nor in the second case ( 0.093 vs 0.039 , column 2$)$ is the difference between point estimates significant at the $5 \%$ level or better. In fact, the returns to higher education in 'ISCO(HE) only' non-graduate jobs may even be lower as the point estimates are insignificantly above zero. Secondly, there is also no statistically significant difference between the rewards to higher education in 'ISCO(HE) only' graduate jobs and the returns in the set of graduate occupations that is common to ours and existing classifiers; be it $\operatorname{ISCO}(1 \& 2)$ or ISCO(RM). In all, the pecuniary returns to higher education in 'ISCO(HE) only' graduate (non-graduate) jobs appear equal to the returns in other graduate (non-graduate) jobs.

Table 6: Labour market outcomes of Graduates, by Classification Method

\begin{tabular}{lcccccc}
\hline & \multicolumn{3}{c}{ Log Hourly Wages } & \multicolumn{3}{c}{ Job Dissatisfaction } \\
\hline & ISCO (HE) & ISCO (1\&2) & ISCO (RM) & ISCO (HE) & ISCO (1\&2) & ISCO (RM) \\
& 2008 & 2008 & 2008 & 2008 & 2008 & 2008 \\
\hline \multirow{2}{*}{ Graduate Job } & $0.261^{* * *}$ & $0.222^{* * *}$ & $0.198^{* * *}$ & $-0.0849^{* * *}$ & $-0.0898^{* * *}$ & $-0.0802^{* * *}$ \\
& $(0.014)$ & $(0.012)$ & $(0.013)$ & $(0.016)$ & $(0.012)$ & $(0.012)$ \\
$\mathrm{N}$ & 14,972 & 14,972 & 14,972 & 22,495 & 22,495 & 22,495 \\
$R^{2}$ & 0.388 & 0.389 & 0.379 & 0.054 & 0.056 & 0.054 \\
\hline \multirow{2}{*}{ Graduate Job } & $0.144^{* * *}$ & $0.192^{* * *}$ & $0.151^{* * *}$ & $-0.0462^{* *}$ & $-0.0587^{* *}$ & $-0.0510^{* *}$ \\
& $(0.013)$ & $(0.015)$ & $(0.017)$ & $(0.017)$ & $(0.020)$ & $(0.019)$ \\
HE & $0.0924^{* * *}$ & $0.156^{* * *}$ & $0.146^{* * *}$ & $0.0449^{* *}$ & $0.0394^{* *}$ & $0.0372^{* *}$
\end{tabular}




\begin{tabular}{lcccccc} 
HE \# & $0.122^{* * *}$ & 0.0272 & $0.0530^{* *}$ & $-0.0426^{*}$ & -0.0340 & -0.0323 \\
Graduate Job & $(0.018)$ & $(0.017)$ & $(0.020)$ & $(0.023)$ & $(0.021)$ & $(0.021)$ \\
\hline $\mathrm{N}$ & 24,192 & 24,192 & 24,192 & 35,683 & 35,683 & 35,683 \\
$R^{2}$ & 0.415 & 0.419 & 0.410 & 0.050 & 0.052 & 0.050 \\
\hline
\end{tabular}

Notes: OLS regression of log real hourly pay in PPP-\$ on graduate job indicator, demographics, economic sector and a set of country dummies. Demographic controls include age-group dummies ( $<25,35-44,45-54,55+$, with 25-34 as reference group) and sex. Sample of the employed graduate (panel I) or high-skilled labour force (panels II) with completed initial education cycle in occupational major groups 1-4. List of countries for wage regressions comprises of BE, CL, CY, CZ, DK, FR, DE, GR, ID, IE, IL, IT, JP, KO, LT, NL, NZ, NO, PL, SK, SI, ES, UK. Regressions of job dissatisfaction additional include data from SG, SE, TR, US. Standard errors in parentheses ${ }^{*} p<0.1,{ }^{* *} p<0.05,{ }^{* * *} p<$ 0.001

Table 6.1: Returns to Higher Education, by Occupational Category

\begin{tabular}{lcc}
\hline & \multicolumn{2}{c}{ Log Hourly Wages } \\
\hline Occupation & ISCO (1\&2) 2008 & ISCO (RM) 2008 \\
\hline Non-graduate [both] & $0.110^{* * *}$ & $0.0927^{* * *}$ \\
Non-graduate [ISCO(HE) only] & {$[0.08,0.14]$} & {$[0.06,0.12]$} \\
& -0.00863 & 0.0387 \\
Graduate [ISCO(HE) only] & {$[-0.14,0.12]$} & {$[-0.13,0.20]$} \\
& $0.177^{* * *}$ & $0.181^{* * *}$ \\
Graduate [both] & {$[0.14,0.21]$} & {$[0.13,0.23]$} \\
& $0.191^{* * *}$ & $0.200^{* * *}$ \\
$N$ & {$[0.16,0.22]$} & $0.17,0.23]$ \\
\hline
\end{tabular}

Notes: Marginal effects of higher education relative to advanced vocational education on log real hourly pay in PPP-\$ and job dissatisfaction after OLS regressions of graduate job categories interacted with higher education qualifications, demographic controls (age-group dummies, sex), economic sector, and a set of country dummies. Sample of the high-skilled labour force with completed initial education cycle in occupational major groups 1-4. For the list of countries with available data see notes of Table $6.95 \%$ confidence intervals in brackets. ${ }^{*} p<0.1,{ }^{* *} p<0.05,{ }^{* * *} p<0.001$

In short, the graduate jobs classifier ISCO(HE)2008 meets multiple validation criteria, and does so better than the realised-matches classifier ISCO(RM)2008 and better than or as well as the traditional classifier ISCO(1\&2)2008. Graduates in non-graduate jobs defined via ISCO(HE)2008 earn less. Furthermore, only ISCO(HE)2008 identifies jobs in which higher education receives positive pecuniary as well as non-pecuniary premia over advanced vocational qualifications. These rewards accrue in traditional graduate jobs, but also in graduate jobs outside the range given by ISCO(1\&2)2008 or ISCO(RM)2008.

\section{The Distribution of Graduate Jobs}

The question posed in our introduction - the motivation for developing a modern graduate jobs indicator - concerned how labour markets have adjusted in the 21 st century to the upskilling of labour forces around the world through the massification of higher education, alongside the ongoing rising demand for high-skilled labour. Across all countries, a third of labour is deployed in graduate jobs according to ISCO(HE)2008. In the following, we examine potential determinants of the distribution of graduate jobs across countries. We expect that cross-national differences in the industry compositions can explain some of the variation in the deployment of labour in graduate jobs. We also test to what extent the quality of graduates relative to other types of high-skilled labour contributes to the remaining cross-national differences in the demand for graduate skills.

\subsection{The deployment of labour in graduate jobs}

As can be seen in Figure 2, the deployment of labour in graduate jobs varies considerably across countries, consistent with the expectations discussed in Section 2. There is a group of countries - 
consisting of the Indonesia, Chile and Turkey- with a distinctly lower share of graduate jobs than the remaining countries. It is lowest in Indonesia, Chile, and Turkey $(<20 \%)$ whilst the labour share in graduate jobs exceeds $50 \%$ in the Netherlands, Finland and Norway. The emerging country ranking may not necessarily comply with intuition as countries with highly complex economies such as Japan or Germany are positioned in the bottom half of the distribution.

\section{Figure 2: Proportion of total working hours in graduate jobs in SAS countries}

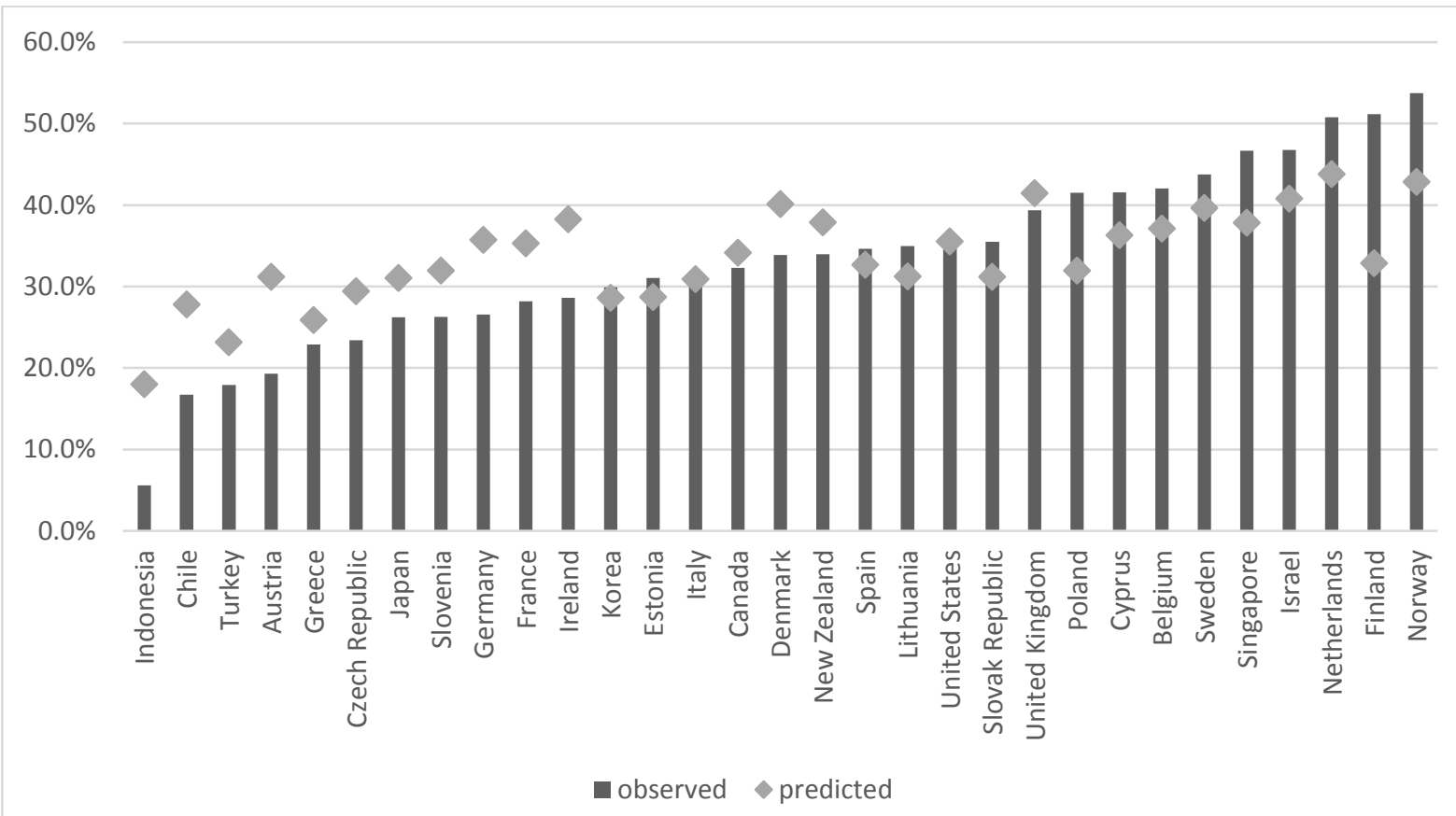

Base: Employed Labour Force 25-54 years. Proportion of total working hours in graduate jobs. Source: SAS 2011/2012 and 2014/2015.

Note: "Observed" represents the observed proportion of working hours in graduate jobs; "Predicted" corresponds to the average predicted number of working hours by country from a saturated linear regression of graduate job status on fully interacted sets of industry dummies, sector dummies and firm size dummies divided by the country-specific average number of working hours. "Surplus" corresponds to the residual between "observed" and "predicted" values.

To some extent, this pattern of cross-country variation might reflect measurable structural factors that affect the demand for graduate labour. Cross-national differences in industrial compositions may account for some of the observed variation. To capture these effects, we ran a saturated linear regression of working hours in graduate jobs on a full set of establishment-size, industry and a public sector dummies. The diamonds in Figure 2 represent the predicted proportion of total working hours in graduate jobs based on the results from the regression. The residual demand for graduate job-hours by country is given by the gap between the columns and diamonds. It provides a measure of national idiosyncrasies that might relate to underlying differences in the relative quality of graduates, prices or production technology.

Accounting thus for differences in industry and establishment-size composition reduces the spread of the labour share of graduate job-hours across the countries in the sample by almost $54 \%$. The residual between the observed and predicted proportion of graduate job-hours varies between -12.4 (Indonesia) 
and 18.3 (Finland) percentage points. One can see for example that Indonesia, Chile, Austria, Germany and Ireland each have a relatively large negative surplus, implying that the low prevalence of graduate jobs is not accounted for by establishment-size and industrial structure. Similarly, the high proportion of labour in graduate jobs in Norway, Poland and especially Finland are not accounted for. Italy, however, has a $30 \%$ share of graduate job-hours which is as predicted by its industrial and establishmentsize structure. Finally, we note the high proportion of graduate jobs in Singapore: while this might seem surprising, given that Singapore has a large migrant population (some 35\% of the workforce in 2010), SAS excluded Singapore's migrant population from the survey, so that we are looking not at the overall economy but at just the permanent residents and Singapore citizens.

\subsection{The role of the higher education system}

If it is not all down to industry and establishment-size structure, to what extent can one account for the remaining considerable cross-country differences in the use of graduate labour? As noted above, vocational and academic skills are, to a certain extent, substitutes. Can thus the design and outcomes of the higher education system explain country differences in the deployment of graduate jobs?

We measured relative skills using SAS own test measures of literacy. Figure 3 suggests that there is an association of relative graduate skills and attributes of the HE system with differences in residual demand for graduate jobs. Across the 31 countries better quality higher education systems (lower dropout rate, higher relative skills) tended to have larger residual demands for graduate jobs. For example, whereas Poland was identified above as a country with a relatively high share of graduate jobs, Figure 3 suggests that this may be related to the high quality of Polish graduates relative to other, vocationally educated, Polish workers. Conversely, Germany's low proportion of graduate jobs looks to be in part accounted for by the fact that its graduates' quality, relative to vocationally-trained German workers, is relatively low; similar remarks could apply to France and Japan. However, Chile's unusually low proportion of graduate jobs seems to be associated with its high drop-out from higher education.

Figure 3: Higher education systems and the 'surplus' labour demand in graduate jobs $(\mathbf{N}=31)$

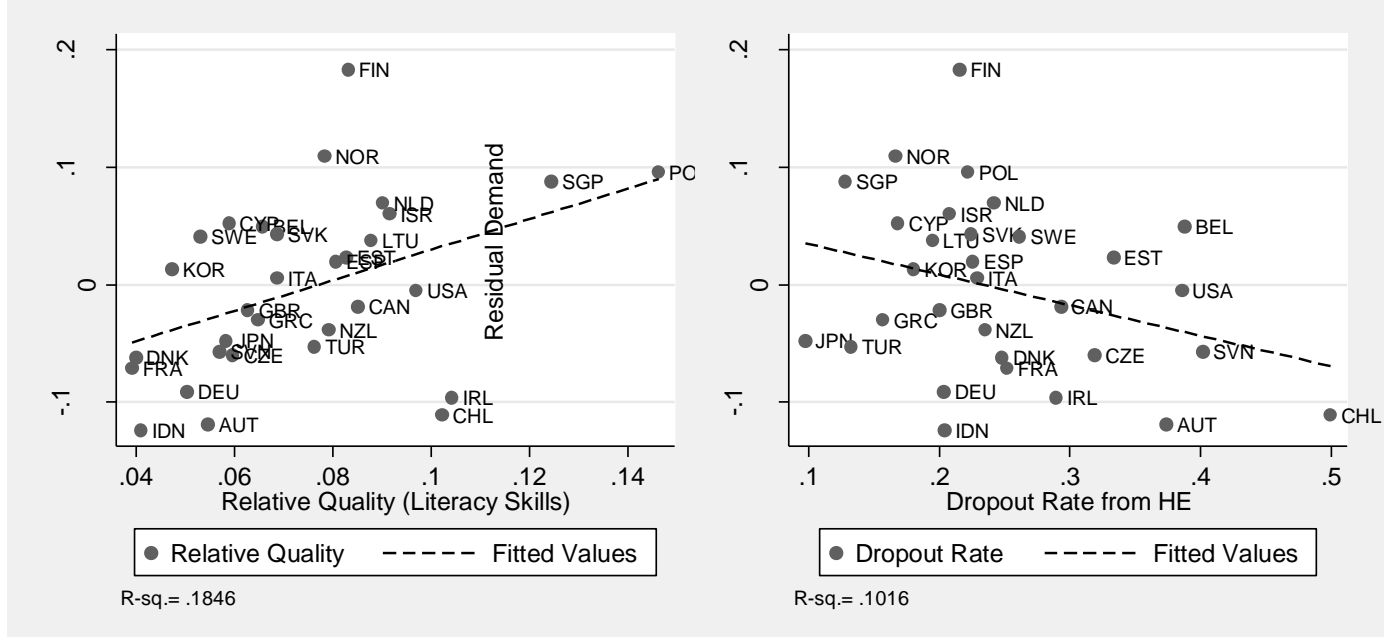


Notes: Trend line based on bivariate regression of the 'surplus' labour demand in graduate jobs on potential macro-level determinants. HE dropout is ratio of the number of people who attended but did not graduate from higher education relative to those that graduated in the age-group $<35$ (SAS, own calculations). Relative graduate skills refer to the skill gap in literacy between graduates and those that attained another high-level post-secondary qualification (SAS, own calculations).

A parsimonious model that combines the HE system indicators with the log GDP per capita explains $40 \%$ of the variation in the surplus demand across countries (Table 7). The first column shows that the surplus of graduate jobs is positively related to the level of development, as might be expected. The second column introduces jointly the indicators of higher education system quality, both of which are significantly associated in the expected way with the surplus. In the third column, these quality indicators retain their significance even after controlling for the level of per capita GDP. But in all these models the outliers remain: for example, Finland's positive surplus demand for labour in graduate jobs remains largely idiosyncratic and we can only speculate here about the reasons. In Finland, the transformation of former vocational education colleges to polytechnics since the early 1990s has contributed to the massive growth in higher education participation and has almost fully replaced advanced vocational qualifications among recent school leavers. The differences between the 'new' and 'old' courses in terms of subsequent graduate labour market outcomes are varied but not strictly positive (Böckerman, 2007; Böckerman et al., 2009). It is conceivable that occupations which required advanced vocational qualifications (i.e., middle-skills jobs such as clerks) before the reform, require nonuniversity higher education certificates after the reform. In conjunction with comparably low skills inequality (Green et al., 2015) this might help account for the unusually large share of graduate jobs in Finland.

Table 7: Multivariate Determinants of the 'surplus' labour demand in graduate jobs $(\mathrm{N}=31)$

\begin{tabular}{lccc}
\hline Determinants & $(1)$ & $(3)$ & $(2)$ \\
Log GDP per & surplus & surplus & surplus \\
capita & $0.0619^{*}$ & & 0.0385 \\
HE Dropout & $(0.033)$ & & $(0.029)$ \\
& & $-0.285^{* *}$ & $-0.279^{* *}$ \\
Relative & & $(0.124)$ & $(0.122)$ \\
Graduate Skills & & $0.00558^{* *}$ & $0.00500^{* *}$ \\
Cons & $-0.650^{*}$ & $(0.002)$ & $(0.002)$ \\
& $(0.347)$ & -0.0512 & -0.443 \\
$R^{2}$ & 0.107 & $(0.046)$ & $(0.301)$ \\
\hline
\end{tabular}

Notes: OLS regression of the 'surplus' demand for graduate jobs on potential macro-level determinants. Log GPD per capita is log of GDP per capita in PPP-\$ (WDI, 2010-2014). HE dropout is ratio of the number of people who attended but did not graduate from higher education relative to those that graduated in the age-group <35 (SAS, own calculations). Relative graduate skills refer to the skill gap in literacy between graduates and those that attained advanced vocational qualifications (SAS, own calculations). Standard errors in parentheses. ${ }^{*} p<0.1,{ }^{* *} p<0.05,{ }^{* * *} p<0.001$

\section{Conclusion}

In this study we have derived a novel, data-driven, statistically-derived indicator for a theoreticallymotivated concept of graduate jobs, based on the use of high skills. The procedure does not rely on 
expert judgement and is thus applicable to other countries and could track occupational upgrading wherever the required skills use data is available. The resulting classifier ISCO(HE)2008 is conceptually valid and explains the wages and job dissatisfaction of graduates at least as well and usually better than the traditional delineation of graduate jobs, which defines them as being exclusively drawn from occupations in ISCO 2008 major groups 1 and 2, and better also than an indicator based on realised matches within occupations.

Our results suggest that the range of graduate jobs in ISCO is often too narrowly focused on traditional professional positions. Graduate jobs encompass a broader field of occupations. We find that across our 31 countries almost a third (32\%) of jobs can be classified as graduate jobs, rather more than the $27 \%$ of jobs that are found with the traditional classification based on belonging to major groups 1 and 2 .

But potential caveats need to be noted. First, occupations can be miscoded with different national coding practices further compounding the issue - an issue that should trouble any classification method. Considerable efforts were made in the SAS to ensure internationally commensurate classification, but some ambiguity remains. Second, our classification approach relies on the decomposition of the selfreport qualification requirements into variation due to more objective work task indicators and an unobserved component that is assumed to summarise measurement and reporting error. In doing this, we assume that work tasks are exogenous to the individual worker. This may be violated if workers have the discretion to mould their jobs to their skills or inflate (deflate) reported job skills together with stated educational requirements. The frequency scales on which work tasks are reported should, however, limit such response patterns. Third, any dichotomous classification system is likely to entail grey areas where the classification decision is close; we have indicated these areas in the appendix list of graduate jobs by country. Moreover, the considerable simplification of a dichotomous graduate/non-graduate job classification is likely to be of value only in a meso- or macro-social context, and inevitably does not discriminate among heterogeneous graduate jobs, for example between university and non-university higher education or graduate and post-graduate skills requirements.

With the above caveats in mind, potential uses of a graduate jobs indicator include applications in employability assessments of universities and colleges, in addition to its potential role in analysing highskill labour markets. Here we have used ISCO(HE) 2008 to illuminate the distribution of graduate jobs: our findings confirm substantial variation in the deployment of graduate jobs across countries. Country differences appear to be accountable in part by the relative skills of graduates compared with substitute labour and by the higher education drop-out rate, both of which we take to be indicators of the relative quality of the higher education system. Nonetheless, substantial country idiosyncrasies remain. Further research on this distribution, and on the disposition of graduate labour in graduate or non-graduate jobs, will be useful. In Green and Henseke (2016b) we have examined the private and social consequences of graduate underemployment across countries. The expansion of higher education across the globe is likely to continue, changing the educational composition of each national labour force. Yet there is no guarantee that the past growth of high-skills demand will persist, as pessimistic commentators have 
pointed out. Monitoring graduate job trends through ISCO(HE) 2008 should be a useful tool to shed light on these processes, alongside analyses of rates of return. Over the longer-term, some occupations will switch between the graduate and non-graduate category, and for this purpose a repeat wave of the SAS in the early 2020s should prove invaluable. In the meantime, trends derived from the changing composition of occupations can be uncovered in the conventional manner, using any regular, ISCOcoded, national labour force survey.

\section{References}

Acemoglu, D., \& Autor, D. (2011). Skills, tasks and technologies: Implications for employment and earnings. Handbook of labor economics, 4, 1043-1171.

Allen, J. (2011). Mobilization of human resources. In The Flexible Professional in the Knowledge Society (pp. 139-176). Springer Netherlands.

Allen, J., \& Van der Velden, R. (Eds.). (2011). The flexible professional in the knowledge society: New challenges for higher education. Springer Science \& Business Media.

Barone, C., \& Ortiz, L. (2011). Overeducation among European University Graduates: a comparative analysis of its incidence and the importance of higher education differentiation. Higher Education, 61(3), 325-337.

Beaudry, P., Green, D. A., \& Sand, B. M. (2014). The declining fortunes of the young since 2000. The American Economic Review, 104(5), 381-386.

Beaudry, P., Green, D. A., \& Sand, B. M. (2016). The Great Reversal in the Demand for Skill and Cognitive Tasks. Journal of Labor Economics, 34(S1), S199-S247.

Björklund, A., \& Jäntti, M. (2012). How important is family background for labor-economic outcomes?. Labour Economics, 19(4), 465-474.

Björklund, A., \& Salvanes, K. G. (2011). Education and Family Background: Mechanisms and Policies. Handbook of the Economics of Education, 3, 201-247.

Böckerman, P. (2007). Polytechnic graduate placement in Finnish manufacturing. Journal of Education and Work, 20(1), 1-16.

Böckerman, P., Hämäläinen, U., \& Uusitalo, R. (2009). Labour market effects of the polytechnic education reform: The Finnish experience. Economics of Education Review, 28(6), 672-681.

Brown, P., Lauder, H., \& Ashton, D. (2010). The global auction: The broken promises of education, jobs, and incomes. Oxford University Press.

Card, D., \& Lemieux, T. (2001). Can Falling Supply Explain the Rising Return to College for Younger Men? A Cohort-Based Analysis. The Quarterly Journal of Economics, 116(2), 705-746.

Cardoso, A. R. (2007). Jobs for young university graduates. Economics Letters, 94(2), 271-277.

Chowdry, H., Crawford, C., Dearden, L., Goodman, A., \& Vignoles, A. (2013). Widening participation in higher education: analysis using linked administrative data. Journal of the Royal Statistical Society: Series A (Statistics in Society), 176(2), 431-457.

Crebert, G., Bates, M., Bell, B., Patrick, C. J., \& Cragnolini, V. (2004). Developing generic skills at university, during work placement and in employment: graduates' perceptions. Higher Education Research \& Development, 23(2), 147-165. 
Eichhorst, W., Rodríguez-Planas, N., Schmidl, R., \& Zimmermann, K. F. (2015). A road map to vocational education and training in industrialized countries. ILR Review, 68(2), 314-337.

Elias, P., \& Purcell, K. (2004). SOC (HE): A classification of occupations for studying the graduate labour market. Research Graduate Careers Seven Years On, Research Paper, 6.

Elias, P., \& Purcell, K. (2013). Classifying graduate occupations for the knowledge society. Institute for employment research. University of Warwick. Futuretrack working paper, 5.

European Commission (2014). Education and Training Monitor 2014. Directorate-General of Education and Culture (DG EAC).

Everitt, B., Landau, S., \& Leese, M. (2001). Cluster analysis. $4^{\text {th }}$ ed. Arnold, London.

Figueiredo, H., Teixeira, P., \& Rubery, J. (2013). Unequal futures? Mass higher education and graduates' relative earnings in Portugal, 1995-2009. Applied Economics Letters, 20(10), 991-997.

Fitzenberger, B., \& Kohn, K. (2006). Skill Wage Premia, Employment, and Cohort Effects: Are Workers in Germany All of the Same Type?. IZA Discussion Paper, 2185.

Ganzeboom, H. B., \& Treiman, D. J. (1996). Internationally comparable measures of occupational status for the 1988 International Standard Classification of Occupations. Social science research, 25(3), 201239.

Giguère, S., \& Froy, F. (2009). A new framework for labour market policy in a global economy. Flexible Policy for More and Better Jobs, 17. OECD Publishing.

Gottschalk, P., \& Hansen, M. (2003). Is the proportion of college workers in noncollege jobs increasing?. Journal of Labor Economics, 21(2), 449-471.

Green, A., Green, F., \& Pensiero, N. (2015). Cross-Country Variation in Adult Skills Inequality. Comparative Education Review, 59(4), 595-618.

Green, F. \& Henseke, G. (2016a). The changing graduate labour market: analysis using a new indicator of graduate jobs. IZA Journal of Labor Policy,10.1186/s40173-016-0070-0

Green, F., \& Henseke, G. (2016b). Should governments of OECD countries worry about graduate underemployment?. Oxford Review of Economic Policy. Forthcoming.

Green, F., \& Zhu, Y. (2010). Overqualification, job dissatisfaction, and increasing dispersion in the returns to graduate education. Oxford Economic Papers, 62(4), 740-763.

Handel, M. J. (2012). Trends in job skill demands in OECD countries. OECD Social, Employment and Migration Working Papers, 120-120.

Heckman, J. J. (2007). The economics, technology, and neuroscience of human capability formation. Proceedings of the National Academy of Sciences, 104(33), 13250-13255.

ILO (2012). International Standard Classification of Occupations: ISCO-08. Geneva: International Labour Organisation.

Jackson, D. (2014). Skill mastery and the formation of graduate identity in Bachelor graduates: evidence from Australia. Studies in Higher Education, 1-20.

Koike, K., \& Inoki, T. (Eds.). (1990). Skill formation in Japan and southeast Asia. University of Tokyo Press.

Levels, M., Levels, M., \& Allen, J. P. (2013). Skill mismatch and skill use in developed countries: Evidence from the PIAAC study. Research Centre for Education and the Labour Market (ROA) Working Paper, 17.

Lindley, J., \& Machin, S. (2016). The Rising Postgraduate Wage Premium. Economica, 83(330), 281306.

Machin, S., \& Van Reenen, J. (1998). Technology and changes in skill structure: evidence from seven OECD countries. Quarterly Journal of Economics, 1215-1244. 
Macmillan, L., \& Vignoles, A. (2013). Mapping the occupational destinations of new graduates. Research Report for the Social Mobility and Child Poverty Commission, London.

Milburn, A. (2009). Unleashing aspiration: the final report of the panel on fair access to the professions. London: Cabinet Office.

O'Leary, N., \& Sloane, P. (2016). Too many graduates? An application of the Gottschalk-Hansen model to young British graduates between 2001-2010. Oxford Economic Papers, 10.1093/oep/gpw027.

OECD 2013a. Education at a Glance 2013, Paris, OECD Publishing.

OECD 2013b. OECD Skills Outlook 2013: First results from the Survey of Adult Skills, Paris, OECD Publishing.

OECD 2013c. Technical Report of the Survey of Adult Skills (PIAAC), Paris, OECD Publishing.

OECD 2014. Education at a Glance 2014: OECD Indicators, Paris, OECD Publishing.

Pastore, F. (2015). The Youth Experience Gap: Explaining National Differences in the School-to-Work Transition. SpringerBriefs in Economics. Springer. 10.1007/978-3-319-10196-5.

Pellizzari, M. \& Fichen, A. (2013), A New Measure of Skills Mismatch: Theory and Evidence from the Survey of Adult Skills (PIAAC), OECD Social, Employment and Migration Working Papers, 153.

Quintini, G. (2011), "Over-Qualified or Under-Skilled: A Review of Existing Literature", OECD Social, Employment and Migration Working Papers, No. 121.

Quintini, G. (2014), Skills at Work: How Skills and their Use Matter in the Labour Market, OECD Social, Employment and Migration Working Papers, No. 158.

Van Reenen, J. (2011). Wage inequality, technology and trade: 21st century evidence. Labour economics, 18(6), 730-741.

Vieira, J. A. C. (2005). Skill mismatches and job satisfaction. Economics letters, 89(1), 39-47.

Wilson, N. R. (2012). Future skills supply and demand in Europe. Cedefop Research Paper, 26.

Zahra, S. A., \& George, G. (2002). Absorptive capacity: A review, reconceptualization, and extension. Academy of management review, 27(2), 185-203. 


\section{Appendix}

This appendix presents the ISCO(HE)2008 classification of graduate jobs in each of the 31 countries. For occupation-country cells with less than five observations in the raw data, classification was based on figures from the corresponding 2-digit occupation; these cases are set in italics. In rare situations where there were insufficient observation at the 2-digit level, the cells are left blank. In a small number of cases confidence in the classification when close to the threshold is limited; we show these with grey shading. Unfortunately, with a few countries -- Austria (AT), Canada (CA), Estonia (EE), Finland (FI), Ireland (IE), Sweden (SE), Singapore (SG), Turkey (TR), United State (US) - we have been unable to calculate standard errors, owing to lack of direct access to restricted relevant microdata data.

Table A.1: List of graduate and non-graduate occupations in major groups 1-4.

\begin{tabular}{|c|c|c|c|c|c|c|c|c|c|c|c|c|c|c|c|c|c|c|c|c|c|c|c|c|c|c|c|c|c|c|c|}
\hline $\begin{array}{l}\text { ISCO 3- } \\
\text { digit }\end{array}$ & AT & BE & CA & CL & CY & $\mathrm{CZ}$ & $\mathrm{DE}$ & DK & EE & ES & FI & FR & GR & ID & IE & IL & IT & JP & KO & LT & NL & NO & NZ & PL & SE & SG & SI & SK & TR & UK & US \\
\hline 111 & 0 & 1 & 1 & 1 & 1 & 1 & & 1 & 1 & 1 & 1 & 1 & & 1 & 1 & 1 & 1 & 1 & 1 & 1 & 1 & 1 & 1 & 1 & 0 & 1 & 1 & 1 & 0 & 1 & 1 \\
\hline 112 & 1 & 1 & 1 & 1 & 1 & 1 & & 1 & 1 & 1 & 1 & 1 & & 1 & 1 & 1 & 1 & 1 & 1 & 1 & 1 & 1 & 1 & 1 & 1 & 1 & 1 & 1 & 0 & 1 & 1 \\
\hline 121 & 1 & 1 & 1 & 1 & 1 & 1 & 1 & 1 & 1 & 1 & 1 & 1 & 1 & 1 & 1 & 1 & 1 & 1 & 1 & 1 & 1 & 1 & 1 & 1 & 1 & 1 & 1 & 1 & 1 & 1 & 1 \\
\hline 122 & 1 & 1 & 1 & 1 & 1 & 1 & 1 & 1 & 1 & 1 & 1 & 1 & 1 & 1 & 1 & 1 & 1 & 1 & 1 & 1 & 1 & 1 & 1 & 1 & 1 & 1 & 1 & 1 & 1 & 1 & 1 \\
\hline 131 & 1 & 1 & 1 & 1 & 1 & 1 & 1 & 1 & 0 & 1 & 1 & 1 & 1 & 1 & 1 & 1 & 1 & 1 & 1 & 1 & 0 & 1 & 0 & 1 & 1 & 1 & 1 & 1 & 1 & 1 & 1 \\
\hline 132 & 0 & 1 & 0 & 1 & 1 & 1 & 1 & 1 & 1 & 1 & 1 & 1 & 1 & 1 & 1 & 1 & 0 & 1 & 1 & 1 & 1 & 1 & 0 & 1 & 1 & 1 & 1 & 1 & 1 & 1 & 1 \\
\hline 133 & 1 & 1 & 1 & 1 & 1 & 1 & 1 & 1 & 1 & 1 & 1 & 1 & 1 & 1 & 1 & 1 & 1 & 1 & 1 & 1 & 1 & 1 & 1 & 1 & 1 & 1 & 1 & 1 & 1 & 1 & 1 \\
\hline 134 & 1 & 1 & 1 & 1 & 1 & 1 & 1 & 1 & 1 & 1 & 1 & 1 & 1 & 1 & 1 & 1 & 1 & 1 & 1 & 1 & 1 & 1 & 1 & 1 & 1 & 1 & 1 & 1 & 1 & 1 & 1 \\
\hline 141 & 0 & 1 & 0 & 0 & 1 & 0 & & 0 & 0 & 0 & 1 & 0 & 0 & 1 & 0 & 0 & 1 & 1 & 0 & 1 & 0 & 0 & 0 & 1 & 1 & 0 & 0 & 0 & 0 & 0 & 0 \\
\hline 142 & 0 & 1 & 0 & 0 & 1 & 0 & & 1 & 0 & 0 & 1 & 1 & 1 & 1 & 0 & 0 & 1 & 1 & 1 & 1 & 0 & 0 & 0 & 1 & 0 & 1 & 1 & 1 & 0 & 0 & 0 \\
\hline 143 & 0 & 1 & 0 & 0 & 1 & 1 & & 1 & 1 & 1 & 1 & 1 & 1 & 1 & 0 & 1 & 1 & 1 & 1 & 1 & 1 & 0 & 0 & 1 & 0 & 1 & 0 & 1 & 0 & 1 & 1 \\
\hline 211 & 1 & 1 & 1 & 1 & 1 & 1 & 1 & 0 & 1 & 1 & 1 & 1 & 1 & 0 & 1 & 1 & 1 & 1 & 1 & 1 & 1 & 1 & 1 & 1 & 1 & 1 & 0 & 1 & 1 & 1 & 1 \\
\hline 212 & 1 & 1 & 1 & 1 & 1 & 1 & 1 & 1 & 1 & 1 & 1 & 1 & 1 & 0 & 1 & 1 & 1 & 1 & 1 & 1 & 1 & 1 & 1 & 1 & 1 & 1 & 1 & 1 & 1 & 1 & 1 \\
\hline 213 & 1 & 1 & 1 & 1 & 1 & 1 & 1 & 1 & 1 & 1 & 1 & 1 & 1 & 0 & 1 & 1 & 1 & 1 & 1 & 1 & 1 & 1 & 1 & 1 & 1 & 0 & 1 & 1 & 1 & 1 & 1 \\
\hline 214 & 1 & 1 & 1 & 1 & 1 & 1 & 1 & 1 & 1 & 1 & 1 & 1 & 1 & 0 & 1 & 1 & 1 & 1 & 1 & 1 & 1 & 1 & 1 & 1 & 1 & 1 & 0 & 1 & 1 & 1 & 1 \\
\hline 215 & 1 & 1 & 1 & 1 & 1 & 1 & 1 & 1 & 1 & 1 & 1 & 1 & 1 & 0 & 1 & 1 & 1 & 1 & 1 & 1 & 1 & 1 & 1 & 1 & 1 & 1 & 1 & 1 & 1 & 1 & 1 \\
\hline 216 & 1 & 1 & 0 & 0 & 1 & 1 & 1 & 1 & 1 & 1 & 1 & 1 & 1 & 0 & 1 & 1 & 1 & 1 & 1 & 1 & 1 & 1 & 1 & 1 & 1 & 1 & 1 & 1 & 1 & 1 & 1 \\
\hline
\end{tabular}




\begin{tabular}{|c|c|c|c|c|c|c|c|c|c|c|c|c|c|c|c|c|c|c|c|c|c|c|c|c|c|c|c|c|c|c|c|}
\hline $\begin{array}{l}\text { ISCO 3- } \\
\text { digit }\end{array}$ & AT & $\overline{B E}$ & CA & CL & $\mathbf{C Y}$ & $\mathbf{C Z}$ & DE & DK & $\mathbf{E E}$ & ES & FI & FR & GR & ID & IE & IL & IT & $\mathbf{J P}$ & KO & LT & NL & NO & $\mathbf{N Z}$ & $\mathbf{P L}$ & SE & SG & SI & SK & TR & UK & US \\
\hline 221 & 1 & 1 & 1 & 1 & 1 & 1 & 1 & 1 & 1 & 1 & 1 & 1 & 1 & & 1 & 1 & \begin{tabular}{l|l|}
1 \\
\end{tabular} & 1 & 1 & 1 & 1 & 1 & 1 & 1 & 1 & 1 & 0 & 1 & 1 & 1 & 1 \\
\hline 222 & 1 & 0 & 1 & 1 & 1 & 0 & 1 & 1 & 1 & 1 & 1 & 1 & 0 & & 1 & 1 & 1 & 0 & 0 & 0 & 1 & 1 & 1 & 1 & 1 & 1 & 0 & 1 & 1 & 1 & 0 \\
\hline 223 & 1 & 0 & 1 & 1 & 1 & 0 & 1 & 1 & 1 & 1 & 1 & 1 & 1 & & 1 & 1 & 1 & 1 & 1 & 1 & 1 & 1 & 1 & 1 & 1 & 1 & 1 & 1 & 1 & 1 & 1 \\
\hline 224 & 1 & 0 & 1 & 1 & 1 & 0 & 1 & 1 & 1 & 1 & 1 & 1 & 1 & & 1 & 1 & \begin{tabular}{l|}
1 \\
\end{tabular} & 1 & 1 & 1 & 1 & 1 & 1 & 1 & 1 & 1 & 1 & 1 & 1 & 1 & 1 \\
\hline 225 & 1 & 0 & 1 & 1 & 1 & 0 & 1 & 1 & 1 & 1 & 1 & 1 & 1 & & 1 & 1 & 1 & 1 & 1 & 1 & 1 & 1 & 1 & 1 & 1 & 1 & 1 & 1 & 1 & 1 & 1 \\
\hline 226 & 1 & 0 & 1 & 1 & 1 & 1 & 1 & 1 & 1 & 1 & 1 & 1 & 1 & & 1 & 1 & 1 & 1 & 1 & 1 & 1 & 1 & 1 & 1 & 1 & 1 & 1 & 1 & 1 & 1 & 1 \\
\hline 231 & 1 & 1 & 1 & 1 & 1 & 1 & 1 & 1 & 1 & 1 & 1 & 1 & 1 & 1 & 1 & 1 & 1 & 1 & 1 & 1 & 1 & 1 & 1 & 1 & 1 & 1 & 1 & 1 & 1 & 1 & 1 \\
\hline 232 & 1 & 1 & 1 & 1 & 1 & 1 & 1 & 1 & 1 & 1 & 1 & 1 & 1 & 1 & 1 & 1 & 0 & 1 & 1 & 1 & 1 & 1 & 1 & 1 & 1 & 1 & 1 & 1 & 1 & 1 & 1 \\
\hline 233 & 1 & 1 & 1 & 1 & 1 & 1 & 1 & 1 & 1 & 1 & 1 & 1 & 1 & 1 & 1 & 1 & 1 & 1 & 1 & 1 & 1 & 1 & 1 & 1 & 1 & 1 & 1 & 1 & 1 & 1 & 1 \\
\hline 234 & 0 & 0 & 1 & 1 & 1 & 1 & 1 & 0 & 1 & 1 & 1 & 1 & 1 & 1 & 1 & 1 & 1 & 1 & 1 & 1 & 1 & 1 & 1 & 1 & 1 & 1 & 1 & 1 & 1 & 1 & 1 \\
\hline 235 & 1 & 1 & 1 & 1 & 1 & 1 & 1 & 1 & 1 & 1 & 1 & 1 & 1 & 1 & 1 & 1 & 1 & 1 & 1 & 1 & 1 & 1 & 1 & 1 & 1 & 0 & 1 & 1 & 1 & 1 & 1 \\
\hline 241 & 1 & 1 & 1 & 1 & 1 & 1 & 1 & 1 & 1 & 1 & 1 & 1 & 1 & 1 & 1 & 1 & 1 & 1 & 1 & 1 & 1 & 1 & 1 & 1 & 1 & 1 & 1 & 1 & 1 & 1 & 1 \\
\hline 242 & 1 & 1 & 1 & 1 & 1 & 1 & 1 & 1 & 1 & 1 & 1 & 1 & 1 & 1 & 1 & 1 & 1 & 1 & 1 & 1 & 1 & 1 & 1 & 1 & 1 & 1 & 1 & 1 & 1 & 1 & 1 \\
\hline 243 & 1 & 1 & 1 & 1 & 1 & 1 & 1 & 1 & 1 & 1 & 1 & 1 & 1 & 1 & 1 & 1 & 1 & 1 & 1 & 1 & 1 & 1 & 1 & 1 & 1 & 1 & 1 & 1 & 0 & 1 & 1 \\
\hline 251 & 1 & 1 & 1 & 1 & 1 & 1 & 1 & 1 & 1 & 1 & 1 & 1 & 1 & 1 & 1 & 1 & 1 & 1 & 1 & 1 & 1 & 1 & 1 & 1 & 1 & 1 & 1 & 1 & 1 & 1 & 1 \\
\hline 252 & 0 & 1 & 0 & 1 & 1 & 1 & 1 & 1 & 0 & 1 & 1 & 1 & 1 & 1 & & 1 & 1 & 1 & 1 & 1 & 1 & 1 & 1 & 1 & 1 & 1 & 1 & 1 & 1 & 1 & 1 \\
\hline 261 & 1 & 1 & 1 & 1 & 1 & 1 & 1 & 1 & 1 & 1 & 1 & 1 & 1 & 0 & 1 & 1 & \begin{tabular}{l|l}
1 \\
\end{tabular} & 1 & 1 & 1 & 1 & 1 & 1 & 1 & 1 & 1 & 1 & 1 & 1 & 1 & 1 \\
\hline 262 & 1 & 0 & 1 & 1 & 1 & 1 & 1 & 1 & 1 & 1 & 1 & 1 & 1 & 0 & 1 & 1 & 1 & 1 & 0 & 1 & 1 & 1 & 1 & 1 & 1 & 1 & 1 & 1 & 0 & 1 & 1 \\
\hline 263 & 1 & 1 & 1 & 1 & 1 & 1 & 1 & 1 & 1 & 1 & 1 & 1 & 1 & 0 & 1 & 1 & 1 & 0 & 1 & 1 & 1 & 1 & 1 & 1 & 1 & 1 & 1 & 1 & 0 & 1 & 1 \\
\hline 264 & 1 & 1 & 1 & 1 & 1 & 1 & 0 & 1 & 1 & 1 & 1 & 1 & 1 & 0 & 1 & 1 & 1 & 1 & 1 & 1 & 1 & 1 & 1 & 1 & 1 & 1 & 1 & 1 & 1 & 1 & 1 \\
\hline 265 & 0 & 0 & 0 & 0 & 1 & 0 & 1 & 1 & 0 & 0 & 1 & 1 & 0 & 0 & 0 & 0 & 0 & 0 & 1 & 0 & 0 & 0 & 0 & 0 & 1 & 0 & 1 & 0 & 0 & 1 & 0 \\
\hline 311 & 0 & 1 & 0 & 0 & 1 & 1 & 0 & 0 & 1 & 1 & 1 & 0 & 1 & 0 & 0 & 0 & 0 & 1 & 1 & 0 & 1 & 1 & 0 & 1 & 1 & 0 & 0 & 1 & 0 & 1 & 0 \\
\hline 312 & 0 & 1 & 0 & 0 & 0 & 0 & 0 & 0 & 0 & 0 & 1 & 0 & 0 & 0 & 0 & 0 & 1 & 0 & 1 & 0 & 1 & 1 & 0 & 1 & 0 & 0 & 0 & 1 & 0 & 1 & 0 \\
\hline 313 & 0 & 0 & 0 & 0 & 1 & 0 & 0 & 0 & 0 & 1 & 0 & 0 & 0 & 0 & 0 & 0 & 0 & 0 & 0 & 0 & 0 & 1 & 0 & 0 & 0 & 0 & 0 & 0 & 0 & 1 & 0 \\
\hline 314 & 0 & 0 & 1 & 0 & 1 & 0 & 0 & 1 & 1 & 1 & 1 & 1 & 0 & 0 & 0 & \begin{tabular}{l|l}
0 \\
\end{tabular} & 1 & 1 & 1 & 0 & 1 & 1 & 0 & 1 & 1 & 0 & 0 & 0 & 0 & 1 & 1 \\
\hline
\end{tabular}




\begin{tabular}{|c|c|c|c|c|c|c|c|c|c|c|c|c|c|c|c|c|c|c|c|c|c|c|c|c|c|c|c|c|c|c|c|}
\hline $\begin{array}{l}\text { ISCO 3- } \\
\text { digit }\end{array}$ & AT & $\mathbf{B E}$ & $\mathbf{C A}$ & $\mathbf{C L}$ & CY & $\mathbf{C Z}$ & DE & DK & $\mathbf{E E}$ & ES & FI & FR & GR & ID & IE & IL & IT & $\mathbf{J P}$ & KO & LT & NL & NO & NZ & $\mathbf{P L}$ & SE & SG & SI & SK & TR & UK & $\mathbf{U S}$ \\
\hline 315 & 0 & 0 & 0 & 0 & 1 & 0 & 0 & 0 & 0 & 0 & 0 & 1 & 0 & 0 & 0 & 0 & 1 & 1 & 1 & 1 & 0 & 0 & 0 & 1 & 1 & 0 & 0 & 0 & 0 & 1 & 0 \\
\hline 321 & 0 & 0 & 0 & 0 & 1 & 0 & 0 & 0 & 0 & 1 & 1 & 0 & 1 & 0 & 1 & 0 & 1 & 0 & 0 & 0 & 1 & 1 & 1 & 0 & 1 & 0 & 0 & 0 & 0 & 0 & 0 \\
\hline 322 & 0 & 0 & 0 & 0 & 1 & 0 & 0 & 0 & 0 & 0 & 1 & 1 & 0 & 0 & 0 & 0 & 1 & 0 & 0 & 0 & 0 & 1 & 0 & 1 & 1 & 0 & 0 & 0 & 0 & 1 & 0 \\
\hline 323 & 0 & 0 & 0 & 0 & 1 & 0 & 0 & 0 & 0 & 0 & 1 & 0 & 0 & 0 & 0 & 0 & 1 & 0 & 0 & 0 & 0 & 1 & 1 & 1 & 1 & 0 & 0 & 0 & 0 & 1 & 0 \\
\hline 324 & 0 & 0 & 0 & 0 & 1 & 0 & 0 & 0 & 0 & 0 & 1 & 0 & 0 & 0 & 0 & 0 & 1 & 0 & 0 & 0 & 0 & 1 & 0 & 1 & 1 & 0 & 0 & 0 & 0 & 0 & 0 \\
\hline 325 & 0 & 1 & 0 & 0 & 1 & 1 & 0 & 0 & 0 & 0 & 1 & 0 & 0 & 0 & 0 & 0 & 1 & 0 & 0 & 0 & 0 & 1 & 0 & 1 & 1 & 0 & 0 & 0 & 0 & 1 & 0 \\
\hline 331 & 0 & 1 & 0 & 0 & 1 & 0 & 0 & 0 & 0 & 1 & 1 & 1 & 0 & 1 & 1 & 0 & 1 & 1 & 1 & 1 & 1 & 1 & 0 & 1 & 1 & 0 & 0 & 0 & 0 & 1 & 0 \\
\hline 332 & 0 & 1 & 0 & 0 & 0 & 0 & 0 & 0 & 0 & 1 & 1 & 0 & 0 & 1 & 0 & 0 & 1 & 0 & 0 & 1 & 1 & 1 & 0 & 1 & 0 & 0 & 0 & 0 & 0 & 0 & 0 \\
\hline 333 & 0 & 0 & 0 & 0 & 1 & 0 & 1 & 0 & 0 & 0 & 1 & 1 & 0 & 1 & 0 & 0 & 1 & 0 & 1 & 1 & 1 & 1 & 0 & 1 & 1 & 0 & 0 & 1 & 0 & 0 & 0 \\
\hline 334 & 0 & 0 & 0 & 0 & 1 & 0 & 1 & 1 & 0 & 1 & 1 & 0 & 1 & 1 & 0 & 1 & 1 & 0 & 1 & 1 & 0 & 1 & 0 & 1 & 0 & 1 & 0 & 1 & 0 & 1 & 1 \\
\hline 335 & 0 & 1 & 0 & 0 & 1 & 0 & 1 & 1 & 0 & 1 & 1 & 0 & 1 & 1 & 0 & 0 & 0 & 1 & 1 & 1 & 1 & 1 & 1 & 1 & 1 & 0 & 0 & 1 & 0 & 1 & 1 \\
\hline 341 & 0 & 0 & 0 & 0 & 1 & 0 & 0 & 0 & 0 & 1 & 1 & 0 & 0 & 0 & 1 & 0 & 1 & 1 & 1 & 0 & 0 & 1 & 0 & 1 & 1 & 0 & 1 & 0 & 1 & 0 & 0 \\
\hline 342 & 0 & 0 & 0 & 0 & 1 & 0 & 0 & 0 & 0 & 0 & 0 & 1 & 1 & 0 & 0 & 0 & 1 & 0 & 0 & 1 & 0 & 0 & 0 & 0 & 0 & 0 & 0 & 0 & 1 & 0 & 0 \\
\hline 343 & 0 & 0 & 0 & 0 & 1 & 0 & 0 & 0 & 0 & 1 & 0 & 0 & 0 & 0 & 0 & 0 & 1 & 0 & 0 & 0 & 0 & 1 & 0 & 1 & 0 & 0 & 0 & 0 & 0 & 1 & 0 \\
\hline 351 & 0 & 1 & 0 & 0 & 1 & 1 & 0 & 0 & 0 & 1 & 1 & 1 & 0 & 1 & 1 & 0 & 1 & 1 & 1 & 1 & 0 & 0 & 0 & 1 & 0 & 0 & 0 & 1 & 0 & 0 & 0 \\
\hline 352 & 0 & 1 & 0 & 0 & 1 & 0 & 0 & 1 & 0 & 1 & 1 & 0 & 0 & 1 & 1 & 0 & 0 & 0 & 0 & 1 & 0 & 0 & 0 & 1 & 0 & 0 & 0 & 1 & 0 & 0 & 0 \\
\hline 411 & 0 & 0 & 0 & 0 & 0 & 0 & 0 & 0 & 0 & 0 & 0 & 0 & 0 & 0 & 1 & 0 & 0 & 0 & 1 & 1 & 0 & 0 & 0 & 1 & 0 & 0 & 0 & 0 & 1 & 0 & 0 \\
\hline 412 & 0 & 0 & 0 & 0 & 0 & 0 & 0 & 0 & 0 & 1 & 1 & 0 & 0 & 1 & 0 & 0 & 0 & 0 & 0 & 0 & 0 & 0 & 0 & 1 & 0 & 0 & 0 & 0 & 0 & 0 & 0 \\
\hline 413 & 0 & 0 & 0 & 0 & 0 & 0 & 0 & 0 & 0 & 0 & 1 & 0 & 0 & 0 & 0 & 0 & 0 & 0 & 0 & 1 & 0 & 0 & 0 & 1 & 0 & 0 & 0 & 0 & 1 & 0 & 0 \\
\hline 421 & 0 & 1 & 0 & 0 & 1 & 0 & 0 & 0 & 0 & 1 & 1 & 0 & 0 & 0 & 0 & 0 & 1 & 0 & 1 & 0 & 0 & 0 & 0 & 1 & 0 & 0 & 0 & 0 & 1 & 0 & 0 \\
\hline 422 & 0 & 0 & 0 & 0 & 0 & 0 & 0 & 0 & 0 & 0 & 1 & 0 & 0 & 0 & 0 & 0 & 0 & 0 & 0 & 0 & 0 & 0 & 0 & 0 & 0 & 0 & 0 & 0 & 0 & 0 & 0 \\
\hline 431 & 0 & 0 & 0 & 0 & 0 & 0 & 0 & 0 & 0 & 1 & 1 & 0 & 0 & 0 & 0 & 0 & 1 & 0 & 0 & 0 & 0 & 0 & 0 & 1 & 0 & 0 & 0 & 0 & 0 & 0 & 0 \\
\hline 432 & 0 & 0 & 0 & 0 & 0 & 0 & 0 & 0 & 0 & 0 & 0 & 0 & 0 & 0 & 0 & 0 & 0 & 0 & 0 & 0 & 0 & 0 & 0 & 0 & 0 & 0 & 0 & 0 & 0 & 0 & 0 \\
\hline 441 & 0 & 0 & 0 & 0 & 0 & 0 & 0 & 0 & 0 & 1 & 0 & 0 & 0 & 0 & 0 & 0 & 0 & 0 & 1 & 0 & 0 & 0 & 0 & 0 & 0 & 0 & 0 & 0 & & 0 & 0 \\
\hline
\end{tabular}




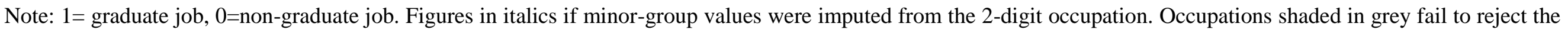

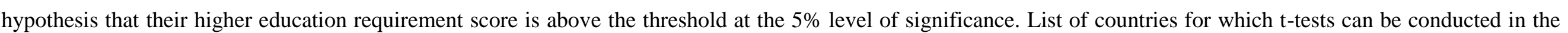
public use-files: BE, CL, CY, CZ, DK, FR, DE, GR, ID, IL, IT, JP, KO, LT, NL, NZ, NO, PL, SK, SI, ES, TR, UK. 
Table A.2: Minor group titles in major groups 1-4.

\begin{tabular}{|c|c|}
\hline $\begin{array}{l}\text { ISCO } \\
\text { code } \\
\end{array}$ & Occupational Title \\
\hline 111 & Legislators and senior officials \\
\hline 112 & Managing directors and chief executives \\
\hline 121 & Business services and administration managers \\
\hline 122 & Sales, marketing and development managers \\
\hline 131 & Production managers in agriculture, forestry and fisheries \\
\hline 132 & Manufacturing, mining, construction, and distribution managers \\
\hline 133 & Information and communications technology service managers \\
\hline 134 & Professional services managers \\
\hline 141 & Hotel and restaurant managers \\
\hline 142 & Retail and wholesale trade managers \\
\hline 143 & Other services managers \\
\hline 211 & Physical and earth science professionals \\
\hline 212 & Mathematicians, actuaries and statisticians \\
\hline 213 & Life science professionals \\
\hline 214 & Engineering professionals (excluding electrotechnology) \\
\hline 215 & Electrotechnology engineers \\
\hline 216 & Architects, planners, surveyors and designers \\
\hline 221 & Medical doctors \\
\hline 222 & Nursing and midwifery professionals \\
\hline 223 & Traditional and complementary medicine professionals \\
\hline 224 & Paramedical practitioners \\
\hline 225 & Veterinarians \\
\hline 226 & Other health professionals \\
\hline 231 & University and higher education teachers \\
\hline 232 & Vocational education teachers \\
\hline 233 & Secondary education teachers \\
\hline 234 & Primary school and early childhood teachers \\
\hline 235 & Other teaching professionals \\
\hline 241 & Finance professionals \\
\hline 242 & Administration professionals \\
\hline 243 & Sales, marketing and public relations professionals \\
\hline 251 & Software and applications developers and analysts \\
\hline 252 & Database and network professionals \\
\hline 261 & Legal professionals \\
\hline 262 & Librarians, archivists and curators \\
\hline 263 & Social and religious professionals \\
\hline 264 & Authors, journalists and linguists \\
\hline 265 & Creative and performing artists \\
\hline 311 & Physical and engineering science technicians \\
\hline 312 & Mining, manufacturing and construction supervisors \\
\hline 313 & Process control technicians \\
\hline 314 & Life science technicians and related associate professionals \\
\hline 315 & Ship and aircraft controllers and technicians \\
\hline 321 & Medical and pharmaceutical technicians \\
\hline 322 & Nursing and midwifery associate professionals \\
\hline 323 & Traditional and complementary medicine associate professionals \\
\hline
\end{tabular}




\begin{tabular}{|r|l|}
\hline \multicolumn{1}{l}{$\begin{array}{l}\text { ISCO } \\
\text { code }\end{array}$} & Occupational Title \\
\hline 324 & Veterinary technicians and assistants \\
\hline 325 & Other health associate professionals \\
\hline 331 & Financial and mathematical associate professionals \\
\hline 332 & Sales and purchasing agents and brokers \\
\hline 333 & Business services agents \\
\hline 334 & Administrative and specialised secretaries \\
\hline 335 & Regulatory government associate professionals \\
\hline 341 & Legal, social and religious associate professionals \\
\hline 342 & Sports and fitness workers \\
\hline 343 & Artistic, cultural and culinary associate professionals \\
\hline 351 & Information and communications technology operations and user support technicians \\
\hline 352 & Telecommunications and broadcasting technicians \\
\hline 411 & General office clerks \\
\hline 412 & Secretaries (general) \\
\hline 413 & Keyboard operators \\
\hline 421 & Tellers, money collectors and related clerks \\
\hline 422 & Client information workers \\
\hline 431 & Numerical clerks \\
\hline 432 & Material-recording and transport clerks \\
\hline 441 & Other clerical support workers \\
\hline & \\
\hline
\end{tabular}

